\title{
Effect of Intraperitoneal Curcumin Instillation on Postoperative Peritoneal Adhesions
}

\author{
Ahmet Türkoğlu $^{a} \quad$ Mesut Gül ${ }^{a} \quad$ Hatice Kurt Yuksel ${ }^{b} \quad$ Ulas Alabalik ${ }^{c}$ \\ Burak Veli Ülger ${ }^{a}$ Omer Uslukaya ${ }^{a}$ Yahya Avcic \\ Departments of ${ }^{\mathrm{a} G e n e r a l ~ S u r g e r y, ~}{ }^{\mathrm{b}}$ Biochemistry and ${ }^{\mathrm{C} P a t h o l o g y, ~ F a c u l t y ~ o f ~ M e d i c i n e, ~ D i c l e ~ U n i v e r s i t y, ~}$ \\ Diyarbakır, Turkey
}

\section{Key Words}

Curcumin · Intraperitoneal adhesion · Adhesion formation

\begin{abstract}
Objective: The aim of this study was to determine the effect of curcumin on adhesion formation in a rat cecum abrasion model. Materials and Methods: Thirty Wistar rats were randomized into three groups; the control group received saline, the curcumin group received $10 \mathrm{mg} / \mathrm{kg}$ of curcumin after cecal abrasion, and in the sham group the abdominal wall was closed without any abrasion to the cecum. On day 15 , adhesions were assessed blindly using a standardized scale, and histopathological samples were taken and examined. Results: There were no incisional hernias or wound dehiscences in any animals of the three groups. A comparison of adhesion scores showed a significant difference between the curcumin (median $=1$ ) and the control group (median $=2 ; p<0.05$ ). The grade of inflammation of the curcumin (median $=1$ ) and the sham (median $=0$ ) group was significantly lower than that of the control group (median $=3 ; p<0.01$ and $p<0.001$, respectively). Hydroxyproline levels were significantly lower in the sham $(48.3 \pm 11.8$ $\mu \mathrm{g} / \mathrm{mg})$ and the curcumin $(63.8 \pm 13.9 \mu \mathrm{g} / \mathrm{mg})$ group com-
\end{abstract}

pared to the control group $(85.7 \pm 22.1 \mu \mathrm{g} / \mathrm{mg} ; \mathrm{p}<0.05)$. Conclusion: These data suggest that curcumin, administered intraperitoneally, was effective in the prevention of peritoneal adhesion formation.

(c) 2014 S. Karger AG, Basel

\section{Introduction}

Intraperitoneal adhesions are a common worldwide problem that causes chronic abdominal pain, dyspareunia, infertility, postoperative ileus and medico-legal issues [1]. The risk for the development of intraperitoneal adhesions after abdominal surgery is reported to be over $90 \%[1,2]$. Postoperative adhesions are the most common cause of small bowel obstruction, responsible for approximately $70-80 \%$ of cases, and are associated with high morbidity and mortality $[1,2]$. While conservative treatment is the primary approach for postoperative ileus, about half of the patients require surgery [2]. Surgical intervention is not without its own complications; after adhesiolysis has been performed, adhesions tend to reform and are associated with an increased morbidity rate and a high risk of relapse of bowel obstruction $[1,2]$.

\begin{tabular}{ll}
\hline KARGER 125:s & $\begin{array}{l}\text { ( ) 2014 S. Karger AG, Basel } \\
1011-7571 / 14 / 0242-0153 \$ 39.50 / 0 \quad \text { Karger }\end{array}$ \\
$\begin{array}{l}\text { E-Mail karger@karger.com } \\
\text { www.karger.com/mpp }\end{array}$ & $\begin{array}{l}\text { Thisis an Open Access article licensed under the terms of the } \\
\text { Creative Commons Attribution-NonCommercial 3.0 Un- } \\
\text { ported license (CC BY-NC) (www.karger.com/OA-license), } \\
\text { applicable to the online version of the article only. Distribu- } \\
\text { tion permitted for non-commercial purposes only. }\end{array}$
\end{tabular}

Assist. Prof. Ahmet Türkoğlu, MD

Department of General Surgery, Faculty of Medicine, Dicle University TR-21280 Diyarbakır (Turkey)

E-Mail ahmetturkoglu04@ hotmail.com 
The pathogenesis of intraperitoneal adhesion formation is still not well understood, and there is no specific treatment. However, the suggestion has been made that inflammatory cells, fibroblasts, the endothelium and the mesothelium of the peritoneal serosa, as well as other factors, are in a complex interplay in the pathogenesis of adhesion formation [3]. Insufficient fibrinolysis is a widely accepted major factor in peritoneal adhesion formation [4], which inevitably occurs if fibrinolysis is insufficient. The two main factors that convert plasminogen into active plasmin, that is tissue plasminogen and urokinaselike plasminogen, are major activators in the fibrinolytic system [4].

Inflammatory mediators also play an important role in adhesion formation. Factors such as transforming growth factor and interleukins decrease the fibrinolytic capacity of the tissue and increase the formation of adhesions [5, 6]. Vascular endothelial growth factor (VEGF), recently found to be expressed by mast cells, has multiple effects on several crucial mechanisms in adhesion formation [7]. VEGF is a potent angiogenic cytokine and has been demonstrated to play a role in early inflammatory responses, wound repair and deposition of fibrinogen [7]. Some medications such as bevacizumab that inhibit the biological activity of human VEGF have been shown to reduce abdominal adhesions [8].

Various material-based strategies are clinically used to cover damaged peritoneal surfaces [9]. Besides, many drug-like agents, including antioxidants, anti-inflammatories, antibiotics, anticoagulants and fibrinolytics, have been shown to prevent the formation of adhesions $[7,10]$. Curcumin, a yellow pigment extracted from the Indian spice tumeric, has been reported to possess pleiotropic effects as an antioxidant as well as to have anti-inflammatory, anticarcinogenic, antibacterial, antiviral, antifungal, antiproliferative and proapoptotic effects [11]. Curcumin has also been shown to increase fibrinolytic activity and cell migration towards the wound area by modulating urokinase-like plasminogen expression [11]. Moreover, curcumin has been shown to inhibit both VEGF secretion and VEGF-mediated angiogenesis [12]. Due to these aforementioned effects, we hypothesize that curcumin could play a role in the prevention of postoperative adhesion formation.

\section{Materials and Methods}

The study was conducted after having obtained approval from the Ethics Committee at Dicle University School of Medicine. The animal care was in accordance with institutional guidelines.

\section{Materials}

The mixture of curcumin was purchased from Sigma Aldrich (C7727; St. Louis, Mo., USA) and was dissolved in dimethyl sulfoxide $(1 \mathrm{mg} / \mathrm{ml})$ in brown glass vials for storage at $4^{\circ} \mathrm{C}$.

\section{Animals}

Thirty male Wistar albino rats weighing 200-250 g were used. The animals were kept in cages under standard conditions with a balanced pellet diet and water. The cages were changed twice a week and the water was changed once a day by experienced staff. The animals were acclimatized for 1 week before the experiments and were kept on a 12-hour light/dark cycle at a constant room temperature and humidity. After adaptation, they were randomly assigned to three different groups: the control, sham and curcumin groups, each including 10 rats.

\section{Anesthesia and Surgical Procedure}

The animals were fasted the night before surgery and then anesthetized with an intramuscular injection of $70 \mathrm{mg} / \mathrm{kg}$ of ketamine (Ketalar; Eczacıbaşı, Istanbul, Turkey). When anesthesia was achieved, the surgical procedures were performed under sterile conditions. Next, a minilaparotomy was performed to gain access to the abdominal cavity. To create a cecal adhesion model, a sterile surgical brush was used to obtain a bleeding surface on the antimesenteric side of the cecum and parietal peritoneum. The peritoneum, fascia and skin were then closed with $3 / 0$ absorbable sutures.

In the sham operation group, the abdominal wall was closed without any abrasion to the cecum. In the control group, the cecal and peritoneal abrasion was conducted and $0.2 \mathrm{ml}$ of saline was administered intraperitoneally before closing the abdomen. In the curcumin group, after cecal and peritoneal abrasion, $10 \mathrm{mg} / \mathrm{kg}$ of curcumin was administrated intraperitoneally before closing the abdomen.

\section{Adhesion Assessment}

On the 15th day of the study, all the animals were anesthetized with an injection of ketamine, and they were euthanized by intracardiac blood collection. A repeat laparotomy was performed to evaluate adhesion formation in the three groups. The cecum and the abdominal sidewall were evaluated for adhesion formation according to the classification of Mazuji et al. [13]. The cecum and adherent abdominal wall were then sent for histopathological evaluation.

\section{Histopathological Evaluation}

Peritoneal healing and fibrosis were quantitated by the measurement of hydroxyproline tissue levels. After fixation of the adhesion, specimens were buffered in formalin (10\%) and were dehydrated and embedded in a paraffin wax. Serial sections of $5 \mu \mathrm{m}$ were stained with hematoxylin and eosin (HE).

The samples were histopathologically examined under light microscopy by a pathologist blinded to the study. A semiquantitative scoring system of the histopathological grading scale of Zühlke was used for the evaluation of the inflammation. Grade I was defined as weak connective tissue, rich cells, old and new fibrin and thin reticulin fibers; grade II was defined as connective tissue with cells and capillaries, and few collagen fibers; grade III was characterized by firmer connective tissue, fewer cells, more vessels and few elastic and smooth-muscle fibers, and grade IV was determined by old, firm granulation tissue which was cell poor and serosal layers which were hardly distinguishable [14] 
Table 1. Distribution of adhesion scores and tissue hydroxyproline levels

\begin{tabular}{lccc}
\hline & $\begin{array}{l}\text { Sham } \\
\text { group }\end{array}$ & $\begin{array}{l}\text { Control } \\
\text { group }\end{array}$ & $\begin{array}{l}\text { Curcumin } \\
\text { group }\end{array}$ \\
\hline $\begin{array}{l}\text { Adhesion scores } \\
\text { Grade 0 }\end{array}$ & 7 & 0 & 3 \\
Grade 1 & 3 & 4 & 5 \\
Grade 2 & 0 & 4 & 2 \\
Grade 3 & 0 & 0 & 0 \\
Grade 4 & 0 & 2 & 0 \\
Grade 5 & 0 & 0 & 0 \\
Hydroxyproline levels & $48.3 \pm 11.8$ & $85.7 \pm 22.1$ & $63.8 \pm 13.9$ \\
\hline
\end{tabular}

Data are either number ( $n=10$ in each group) or mean \pm SD $(\mu \mathrm{g} / \mathrm{mg})$. Significant differences $(\mathrm{p}<0.05)$ were found for the adhesion scores between the curcumin and control groups and for the hydroxyproline levels of the sham and curcumin groups compared to the control group.

\section{Determination of Tissue Levels of Hydroxyproline}

Because collagen plays an important role in the development of postoperative adhesions and hydroxyproline is a major component of the protein collagen, the extent of collagen deposition in the adhesion tissues was determined using the hydroxyproline analysis. From an adhesion, $1 \mathrm{~g}$ of tissue was hydrolyzed in $1 \mathrm{ml}$ of acidic buffer at $121^{\circ} \mathrm{C}$ for $5 \mathrm{~h}$. Then, the tissue was centrifuged at $5,000 \mathrm{rpm}$ for $20 \mathrm{~min}$. The absorbance of this material was evaluated colorimetrically (spectrometrically), with a wave length maximum of $560 \mathrm{~nm}$ and at $121^{\circ} \mathrm{C}$. Hydroxyproline levels were calculated in micrograms per milligram of tissue.

\section{Statistical Analyses}

Statistical evaluation was made using MedCalc software version 12.4.0. The Mann-Whitney $U$ test was used to evaluate continuous variables. Two-sided $\mathrm{p}$ values are given and $\mathrm{p}<0.05$ was considered to be the limit of significance.

\section{Results}

All animals completed the study. No congenital adhesions were noted at the initial laparotomy. There were no incisional hernias or wound dehiscences present.

\section{Macroscopic Adhesion Scores}

The adhesion scores for each group are shown in table 1 . On comparing adhesion scores, a significant difference was found between the curcumin and the control groups $(\mathrm{p}<0.05)$. However, the curcumin and sham groups ( $p>0.05)$ did not show any significant differences $(p>0.05)$. An example of abdominal adhesion tissue in the control group is shown in figure 1 .

Effect of Curcumin on Postoperative Adhesions

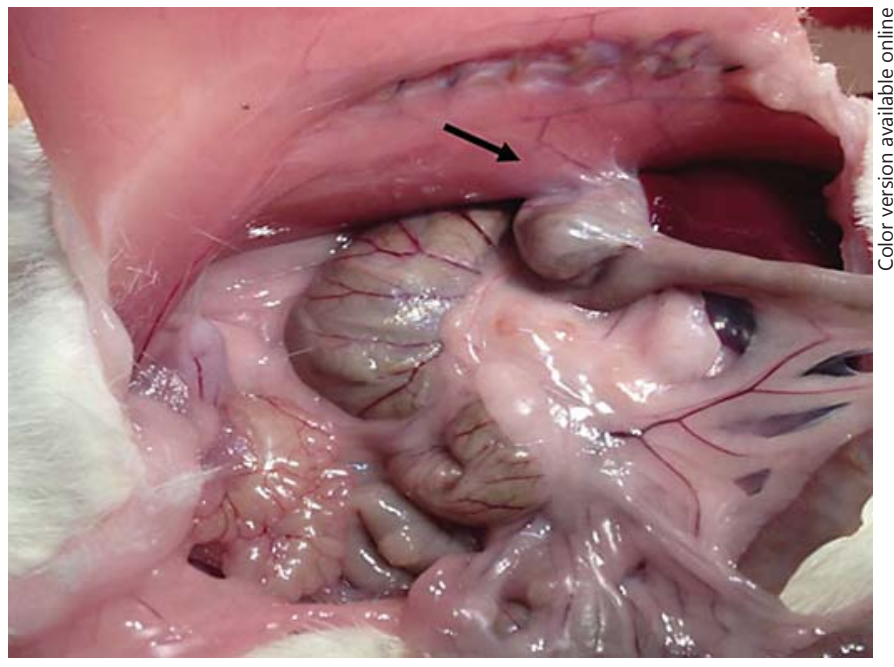

Fig. 1. A rat from the control group with peritoneal adhesion formation.

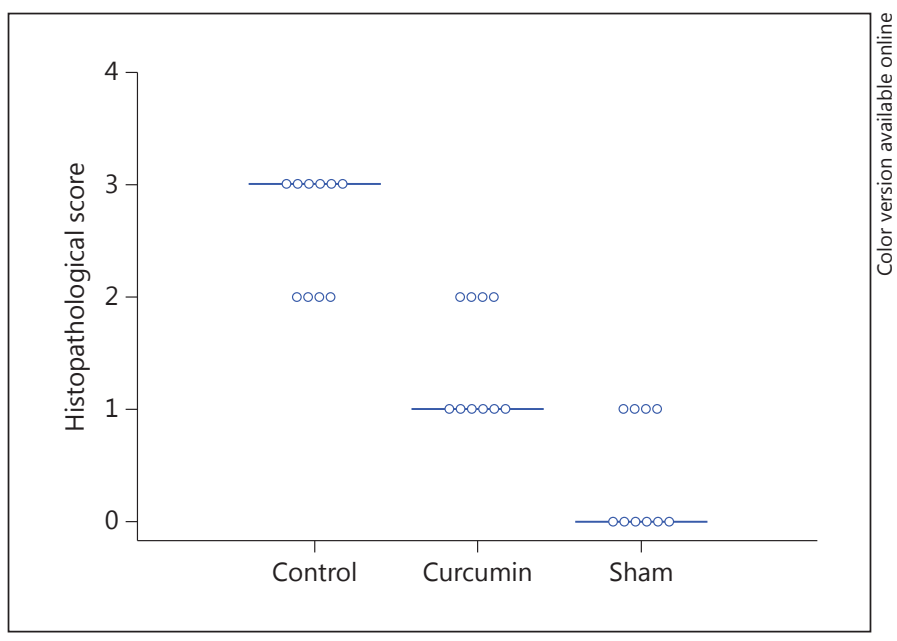

Fig. 2. The histopathological scores in each group: those of the curcumin and sham groups were significantly lower than those of the control group ( $\mathrm{p}=0.0016$ and $\mathrm{p}=0.0001$, respectively).

\section{Histopathological Results}

The Zühlke scores were significantly lower in the curcumin (median $=1)$ and sham (median $=0$ ) groups compared to the control group (median $=3 ; \mathrm{p}<0.01$ and $\mathrm{p}<$ 0.001 , respectively; fig. 2,3 ). There were 6 animals in the control group with a Zühlke grade 3 score whilst the other groups had no animals with a grade 3 score. Six animals in the curcumin group had grade 1 and the others had grade 2 scores. Six animals in the sham group had grade 0 and the others had grade 1 scores. The sham group (me-

Med Princ Pract 2015;24:153-158 
Fig. 3. a An area representing grade 3 adhesion according to the microscopic classification system of Zühlke in a rat from the control group. b A nonadhesion area in a rat from the sham group. c An area representing grade 3 adhesion in a rat from the curcumin group. HE stain. Original magnification. $\mathbf{a} \times 200$. b, $\mathbf{c} \times 100$.

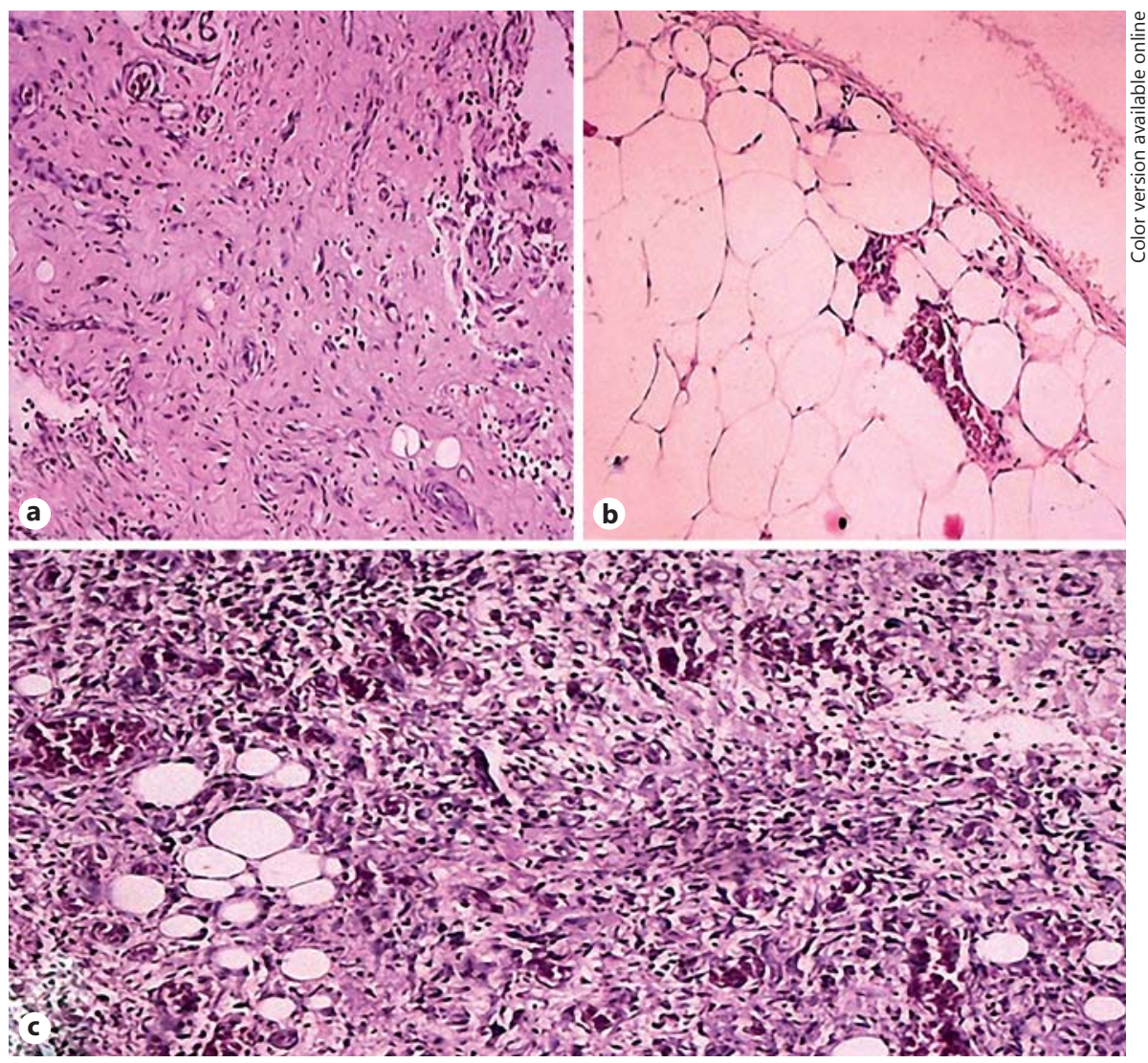

dian $=0$ ) had significantly lower Zühlke scores compared to the curcumin group (median $=1 ; \mathrm{p}<0.01$ ). Microscopic findings were similar to macroscopic findings.

\section{Quantitative Analysis of Hydroxyproline}

Because collagen plays an important role in the development of postoperative adhesions and hydroxyproline is a major component of the protein collagen, the extent of collagen deposition in the adhesion tissues was determined using hydroxyproline analysis. Hydroxyproline levels were significantly lower in the sham $(48.3 \pm 11.8 \mu \mathrm{g} /$ $\mathrm{mg})$ and curcumin groups $(63.8 \pm 13.9 \mu \mathrm{g} / \mathrm{mg})$ compared to the control group $(85.7 \pm 22.1 \mu \mathrm{g} / \mathrm{mg} ; \mathrm{p}<0.05$; table 1$)$.

\section{Discussion}

Both surgeons' adhesion scorings and the histopathological grading showed significantly low adhesion scores in the curcumin group in comparison to the control group. Hence, the present study showed that curcumin effectively decreased the experimental postsurgical abdominal adhe- sion rate. Hydroxyproline levels were significantly lower in the curcumin group compared to the control group, thereby indicating that intraperitoneally administered curcumin decreased collagen synthesis. In some patients peritoneal tissues have a high tendency to develop adhesions, probably due to a reduced ability of the peritoneum to degrade fibrin deposits. It is widely accepted that the early fibrinolytic capacity plays an important role in the formation of adhesions [15]. In the first few days after peritoneal injury, fibrinolysis prevents adhesion formation during healing of the peritoneum. However, if the fibrinolysis process is ineffective, adhesion formation is inevitable. Fibrinolysis is carried out by the transition of plasminogen to plasmin, an enzyme with a broad proteolytic activity. In humans, it has been shown that peritoneal plasminogen activation is decreased during surgery, leading to subsequent adhesion formation [15]. Madhyastha et al. [11] demonstrated that curcumin treatment resulted in an increase in fibrinolytic activity around the wound area via an upregulation of urokinase-like plasminogen activator mRNA and protein.

Since VEGF has been shown to play a central role in the formation of postoperative intra-abdominal adhesions, 
anti-VEGF monoclonal antibodies have been suggested for antiadhesion treatment. Ignjatovic et al. [8] stated that a single intraperitoneal dose of bevacizumab, a recombinant humanized monoclonal antibody that binds to and inhibits the biological activity of human VEGF, diminished both the grade and severity of peritoneal adhesions in a rat adhesion model. Fortunately, this therapy did not disrupt wound healing in a clinically important manner. Binion et al. [16] demonstrated that COX-2 plays an important role in VEGF-induced angiogenesis and curcumin blocks both COX-2 expression and angiogenesis induced by VEGF. They suggested that these findings may provide an understanding of the beneficial effects of curcumin in conditions such as chronic inflammation and cancer. Gururaj et al. [17] demonstrated a time-dependent response of curcumin in VEGF inhibition in endothelial cells. Similarly, curcumin has been shown to inhibit the transcript levels of VEGF in breast cancer cells [18]. Moreover, Bae et al. [19] found that curcumin suppressed transcriptional activity of HIF-1a, leading to a decrease in the expression of VEGF.

An important question that remains to be answered about intraperitoneal curcumin administration is whether or not it impairs wound healing. In our study, no wound dehiscences or abdominal wall hernias were seen in the groups, showing that administration of curcumin intraperitoneally does not disrupt wound healing in a clinically important fashion. Several studies have shown the nontoxic nature and beneficial effects of curcumin as a wound-healing agent $[20,21]$.

Jomezadeh et al. [22] claimed that curcumin was not effective in reducing postoperative peritoneal adhesion in rats. However, they performed relaparotomy on the 5th postoperative day to evaluate adhesion formation. Within the first 5 days after surgery, early fibrinolysis encourages peritoneal healing. If enough fibrinolysis does not occur within 5-7 days of the injury, the temporary fibrin matrix gradually becomes more organized and leads to adhesion formation. Therefore, adhesion formation is best evaluated after $7-10$ days of the initial surgery $[4,8]$. In our opinion, the 5 th postoperative day is a very early point at which to evaluate adhesion formation. Therefore, we performed a second laparotomy 15 days after the first operation.

\section{Conclusion}

The present study shows that curcumin appeared to be safe and effective in the prevention of postoperative intra-abdominal adhesion formation in the rat. Due to the nontoxic nature of curcumin, we suggest that it could be used for the prevention of peritoneal adhesion formation. However, further studies are needed to determine the most suitable intraperitoneal dose of curcumin for peritoneal adhesions.

\section{Acknowledgements}

We are grateful to Dicle University Scientific Research Projects (DUBAP) for their sponsorship of the English editing of this manuscript and to the experienced staff of the Health Research Center (DÜSAM) Laboratory of Dicle University, Veterinary Doctor Ferhat Demir and Mehmet Tahir Mujde, for their efforts in the care of the animals and experiments.

\section{Disclosure Statement}

The authors have no conflicts of interest to declare.

\section{References}

Effect of Curcumin on Postoperative Adhesions
1 Menzies D, Ellis H: Intestinal obstruction from adhesions: how big is the problem? Ann R Coll Surg Engl 1990;72:60-63.

2 Ellis $\mathrm{H}$, Crowe A: Medico-legal consequences of post-operative intra-abdominal adhesions. Int J Surg 2009;7:187-191.

3 Brochhausen C, Schmitt VH, Planck CN, et al: Current strategies and future perspectives for intraperitoneal adhesion prevention. J Gastrointest Surg 2012;16:1256-1274.

4 Schnüriger B, Barmparas G, Branco BC, et al: Prevention of postoperative peritoneal adhesions: a review of the literature. Am J Surg 2011;201:111-121.

5 Lucas PA, Warejcka DJ, Young HE, et al: Formation of abdominal adhesionsis inhibited by antibodies to transforming growth factor- $\beta 1$. J Surg Res 1996;65:135-138.
6 Saba AA, Kaidi AA, Godziachvili V, et al: Effects of interleukin-6 and its neutralisating antibodies on peritoneal adhesion formation and wound healing. Am Surg 1996;62:569572.

7 Cahill RA, Wang JH, Soohkai S, et al: Mast cells facilitate local VEGF release as an early event in the pathogenesis of postoperative peritoneal adhesions. Surgery 2006;140:108-112.

8 Ignjatovic $\mathrm{D}$, Aasland $\mathrm{K}$, Pettersen $\mathrm{M}$, et al Intra-abdominal administration of bevacizumab diminishes intra-peritoneal adhesions. Am J Surg 2010;200:270-275.

9 Brochhausen C, Schmitt VH, Rajab TK, et al: Intraperitoneal adhesions - an ongoing challenge between biomedical engineering and the life sciences. J Biomed Mater Res A 2011; 98:143-156. 
10 Irkorucu O, Ferahköșe Z, Memiş L, et al: Reduction of postsurgical adhesions in a rat model: a comparative study. Clinics (Sao Paulo) 2009;64:143-148

11 Madhyastha R, Madhyastha H, Nakajima Y, et al: Curcumin facilitates fibrinolysis and cellular migration during wound healing by modulating urokinase plasminogen activator expression. Pathophysiol Haemost Thromb 2009;37:59-66.

12 Yoysungnoen $\mathrm{P}$, Wirachwong $\mathrm{P}$, Bhattarakosol P, et al: Effects of curcumin on tumor angiogenesis and biomarkers, COX-2 and VEGF, in hepatocellular carcinoma cell-implanted nude mice. Clin Hemorheol Microcirc 2006;34:109-115.

13 Mazuji MK, Kalambaheti K, Pawar B: Prevention of adhesions with polyvinyl pyrrolidone: preliminary report. Arch Surg 1964;89:10111015.
14 Ozel H, Avsar FM, Topaloglu S, et al: Induction and assessment methods used in experimental adhesion studies. Wound Rep Reg 2005; 13:358-364.

15 Holmdahl R, Ivarsson ML: The role of cytokines, coagulation, and fibrinolysis in peritoneal tissue repair. Eur J Surg 1999;165:10121019.

16 Binion DG, Otterson MF, Rafiee P: Curcumin inhibits VEGF-mediated angiogenesis in human intestinal microvascular endothelial cells through COX-2 and MAPK inhibition. Gut 2008;57:1509-1517.

17 Gururaj AE, Belakavadi M, Venkatesh DA, et al: Molecular mechanisms of anti-angiogenic effect of curcumin. Biochem Biophys Res Commun 2002;297:934-942.
18 Shao ZM, Shen ZZ, Liu CH, et al: Curcumin exerts multiple suppressive effects on human breast carcinoma cells. Int J Cancer 2002;98: 234-240.

19 Bae MK, Kim SH, Jeong JW, et al: Curcumin inhibits hypoxia-induced angiogenesis via down-regulation of HIF-1. Oncol Rep 2006; 15:1557-1562.

20 Panchatcharam M, Miriyala S, Gayathri VS, et al: Curcumin improves wound healing by modulating collagen and decreasing reactive oxygen species. Mol Cell Biochem 2006;290:87-96.

21 Sun J, Yang D, Li S, et al: Effects of curcumin or dexamethasone on lung ischaemia - reperfusion injury in rats. Eur Respir J 2009;33: 398-404.

22 Jomezadeh V, Mohammadpour AH, Rajabi $\mathrm{O}$, et al: Evaluation of curcumin effects on post-operative peritoneal adhesion in rats. Iran J Basic Med Sci 2012;15:1162-1167. 